\title{
SIMULAÇÃO DO PROCESSO DE PURIFICAÇÃO DO ÁCIDO LÁCTICO EM UM SISTEMA DE DESTILAÇÃO REATIVA
}

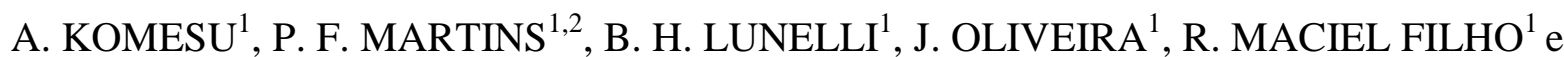

M.R.WOLF MACIEL ${ }^{1}$

\author{
${ }^{1}$ Universidade Estadual de Campinas, Faculdade de Engenharia Química \\ ${ }^{2}$ Universidade Federal deSão Paulo, Departamento de Ciências Exatas e da Terra \\ E-mail para contato: andrea_komesu@hotmail.com
}

\begin{abstract}
RESUMO- Neste trabalho, uma planta virtual composta por duas colunas de destilação reativa (uma para a reação de esterificação do ácido láctico com etanol, e outra para a reação de hidrólise do lactato de etila com água) e uma seção para recuperação de etanol foi desenvolvida para a purificação do ácido láctico proveniente da fermentação. A planta virtual do processo foi desenvolvida com o auxílio do Simulador Aspen Plus ${ }^{\circledR}$. As propriedades termodinâmicas e cinéticas da reação foram primeiramente analisadas e, posteriormente, as colunas de destilação reativa foram projetadas de modo a se obter maiores purezas de lactato de etila e ácido láctico. UNIQUAC foi utilizado para o cálculo dos coeficientes de atividade. Os resultados mostraram que o processo de purificação do ácido láctico proposto neste trabalho tem grande potencial para obtenção de ácido láctico com elevada pureza $(\sim 85 \%)$.
\end{abstract}

\section{INTRODUÇÃO}

O desenvolvimento de processos biotecnológicos industriais que utilizem recursos naturais renováveis é uma necessidade que se faz presente nos dias atuais, dada a preocupação com o abastecimento de petróleo e o desenvolvimento sustentável. Um grande interesse pelos processos fermentativos para produção de ácidos carboxílicos a partir de recursos renováveis tem sido despertado, sendo a produção de ácido láctico uma das mais importantes entre os ácidos orgânicos. A grande variedade de aplicações e o desenvolvimento de novos usos e produtos, como na produção de polímeros biodegradáveis (poli-ácido láctico), solventes verdes e químicos oxigenados, fizeram com que a produção de ácido láctico crescesse consideravelmente nas últimas décadas e estimulasse a pesquisa por tecnologias que tornem o processo mais viável economicamente. No caso do ácido láctico, o desenvolvimento de um método eficaz de separação e purificação do ácido a partir do caldo de cana-de-açúcar fermentado é de suma importância, pois o processo de separação e purificação corresponde a $50 \%$ do custo de produção (Wasewaret al., 2002).

O processo de destilação reativa é aplicado especificamente em reações químicas reversíveis na fase líquida, em que a reação de equilíbrio limita a conversão dos reagentes (Seoet al., 1999). A destilação reativa tem sido proposta como uma técnica promissora para a recuperação de ácido láctico com elevada pureza e elevado rendimento do caldo de fermentação (Kumaret al., 2006a) devido a muitos motivos, entre os quais pode-se destacar a redução dos custos com equipamentos na esterificação, melhora na conversão dos reagentes,melhora na seletividade dos produtos 
desejados, significativa redução da quantidade de catalisador requerido para um mesmo grau de conversão e possibilita a integração energética para uma reação exotérmica onde o calor de reação pode ser usado para fornecer o calor de vaporização e reduzir o calor necessário no refervedor.

Diversos estudos variando os parâmetros e condições operacionais para a recuperação do ácido láctico nas destilações reativas têm sido reportadas (Seoet al., 1999; Asthanaet al., 2005;Kumaret al., 2006b; Lunelliet al., 2010; Moet al., 2011;Edrederet al., 2011; Mujtabaet al.; 2012). Novos estudos para a recuperação do ácido láctico por meio da destilação reativa são necessários, de modo a se desenvolver um processo mais economicamente atraente e eficiente para aplicações industriais.

Assim, este trabalho pretende contribuir com o desenvolvimento de uma planta virtual de um processo de purificação do ácido láctico a partir do caldo de fermentação, para obtenção do mesmo com elevada pureza $(\sim 85 \%)$.

\section{REAÇÕES PARA A RECUPERAÇÃO DO ÁCIDO LÁCTICO}

Para a recuperação do ácido láctico estão envolvidas uma reação de esterificação e uma reação de hidrólise. A reação de esterificação do ácido láctico com etanol é reversível e exotérmica, dada pela Equação 1, e a reação de hidrólise do ácido láctico com água é reversível e endotérmica, dada pela Equação 2.

Esterificação: $\mathrm{C}_{3} \mathrm{H}_{6} \mathrm{O}_{3}+\mathrm{C}_{2} \mathrm{H}_{5} \mathrm{OH} \rightarrow \mathrm{C}_{5} \mathrm{H}_{10} \mathrm{O}_{3}+\mathrm{H}_{2} \mathrm{O}$

Ácido láctico+etanol $\rightarrow$ lactato de etila +água

Hidrólise: $\mathrm{C}_{5} \mathrm{H}_{10} \mathrm{O}_{3}+\mathrm{H}_{2} \mathrm{O} \rightarrow \mathrm{C}_{3} \mathrm{H}_{6} \mathrm{O}_{3}+\mathrm{C}_{2} \mathrm{H}_{5} \mathrm{OH}$

(Erro!

Nenhum texto com o estilo especificado foi encontrado no documento.)

Lactato de etila+água $\rightarrow$ ácido láctico+etanol

\section{TERMODINÂMICA E CINÉTICA DO PROCESSO}

A seleção de um modelo termodinâmico para determinar o coeficiente de atividade é de fundamental importância na predição do equilíbrio de fases. Dados experimentais disponíveis na literatura para o sistema binário água e ácido láctico (Sanz et al., 2003), etanol e água (Carey e Lewis et al., 1932) e etanol e lactato de etila (Peña-Tejedoret al., 2005) foram comparados com os dados gerados pelos modelos termodinâmicos NRTL (Non-Randow, Two-Liquid) e UNIQUAC (Universal Quase-Chemical) e o método UNIFAC (UNIQUAC FunctionalgroupActivityCoefficient) no simulador Aspen Plus ${ }^{\circledR}$. O modelo termodinâmico escolhido para o cálculo do coeficiente de atividade na fase líquidafoi o UNIQUAC pela boa concordância com os dados experimentais e a equação de estado de HaydenO'Connell foi escolhido para o cálculo do coeficiente de fugacidade da fase vapor. A correlação proposta por Hayden e O'Connell (1975) permite estimar os coeficientes viriais para compostos polares, apolares e que formem associações na fase vapor (Oliveira, 2003).

Os valores dos parâmetros para a cinética de esterificação do ácido láctico com etanol foram 
obtidos de Delgado et al. (2007), conforme Tabela 1 e Equação 3.

Tabela 1- Parâmetros para a cinética de esterificação e hidrólise

\begin{tabular}{ccc}
\hline Reação & $k_{e}^{0}\left(\mathrm{~mol} \mathrm{~min}^{-1} \mathrm{~g}^{-1}\right)$ & $E_{A, e}\left(\mathrm{~kJ} \mathrm{~mol}^{-1}\right)$ \\
\hline Esterificação & $5,298 \times 10^{8}$ & 64,44 \\
Hidrólise & $3,844 \times 10^{7}$ & 56,05 \\
\hline
\end{tabular}

Os parâmetros cinéticos foram obtidos para a reação de esterificação homogênea sem a presença de catalisador externo. A hidrólise do lactato de etila é uma importante reação que pode ser usada para a obtenção de ácido láctico de elevada pureza. Entretanto, somente o trabalho de Delgado et al. (2007) apresenta um estudo sobre a cinética de hidrólise do lactato de etila.

$$
k_{e}=k_{e}^{0} \exp \left(\frac{-E_{A, e}}{R T}\right)
$$

onde $k_{e}^{0}\left(\operatorname{mol~} \min ^{-1} \mathrm{~g}^{-1}\right)$ é o fator pré-exponencial de Arrhenius, $E_{A, e}\left(\mathrm{~kJ} \mathrm{~mol}^{-1}\right)$ é a energia de ativação, $\mathrm{R}$ é a constante universal dos gases e $\mathrm{T}$ é a temperatura absoluta.

\section{RESULTADOS E DISCUSSÕES}

O fluxograma doprocessoproposto para a purificação do ácido láctico é mostrado na Figura 1. A Tabela 2 mostra as condições iniciais para as correntes de alimentação e a Tabela 3 mostra as especificações das colunas usadas na simulação do processo de esterificação e hidrólise do ácido láctico.

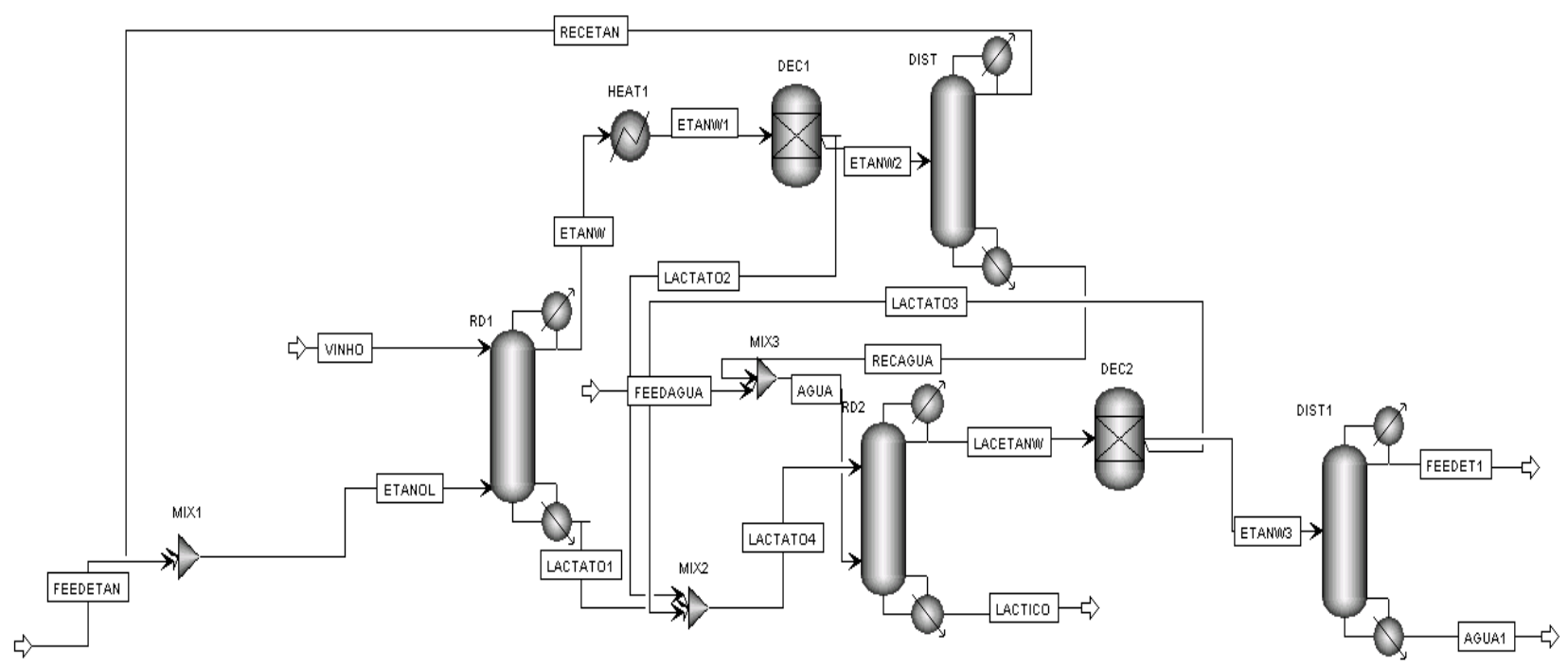

Figura 1-Fluxograma do processo de esterificação e hidrólise do ácido láctico.

Na coluna RD1, coluna de destilação reativa onde ocorre a reação de esterificação, a 
corrente de VINHO contendo ácido láctico e água proveniente do processo fermentativo de produção do ácido láctico é alimentada no topo da coluna e a corrente de ETANOL contendo etanol e água é alimentada no fundo da coluna. O produto de topo da coluna RD1, corrente ETANW, é enviado para a etapa de recuperação do etanol. A corrente de fundo da coluna RD1 é alimentada em uma coluna de destilação reativa RD2 para a reação de hidrólise. O produto de topo da coluna RD2, corrente LACETANW, é enviado para a etapa de recuperação do etanol e do lactato de etila e ácido láctico é recuperado no produto de fundo. Os perfis de composição mássica da fase líquida e da fase vapor das colunas RD1 e RD2 são mostrados nas Figuras 2 e 3, respectivamente.

Tabela 2- Condições iniciais para as correntes de alimentação 1

\begin{tabular}{cccccc}
\hline Corrente & $\begin{array}{c}\text { Temperatura } \\
\left({ }^{\circ} \mathrm{C}\right)\end{array}$ & $\begin{array}{c}\text { Vazão de } \\
\text { água }(\mathrm{kg} / \mathrm{h})\end{array}$ & $\begin{array}{c}\text { Vazão de } \\
\text { ácido láctico } \\
(\mathrm{kg} / \mathrm{h})\end{array}$ & $\begin{array}{c}\text { Vazão de } \\
\text { etanol } \\
(\mathrm{kg} / \mathrm{h})\end{array}$ & $\begin{array}{c}\text { Vazão de } \\
\text { lactato de } \\
\text { etila }(\mathrm{kg} / \mathrm{h})\end{array}$ \\
\hline VINHO & 34,00 & 57,400 & 40,100 & - & - \\
ETANOL & 78,50 & 39,000 & - & 261,000 & - \\
AGUA & 100,00 & 99,395 & $3,143 \mathrm{E}-07$ & $7,053 \mathrm{E}-12$ & 0,181 \\
LACTATO4 & 113,07 & 6,901 & $3,570 \mathrm{E}-11$ & 0,024 & 53,311 \\
\hline
\end{tabular}

Tabela3- Especificações das colunasusadas na simulação do processo de esterificação e hidrólise do ácido láctico

\begin{tabular}{cccccc}
\hline Coluna & $\begin{array}{c}\text { Número de } \\
\text { estágios }\end{array}$ & $\begin{array}{c}\text { Número de } \\
\text { estágios } \\
\text { reativos }\end{array}$ & $\begin{array}{c}\text { Holdup } \\
\text { (molar) }\end{array}$ & $\begin{array}{c}\text { Razão de } \\
\text { refluxo }(\mathrm{mol})\end{array}$ & $\begin{array}{c}\text { Vazão de } \\
\text { resíduo } \\
\text { (kmol/h) }\end{array}$ \\
\hline RD1 & 29 & 23 & 500 & 0,772 & 0,446 \\
DIST & 30 & - & - & 1 & 3,576 \\
RD2 & 29 & 23 & 500 & 0,9 & 0,82 \\
DIST1 & 30 & - & - & 1,5 & 4,584 \\
\hline
\end{tabular}

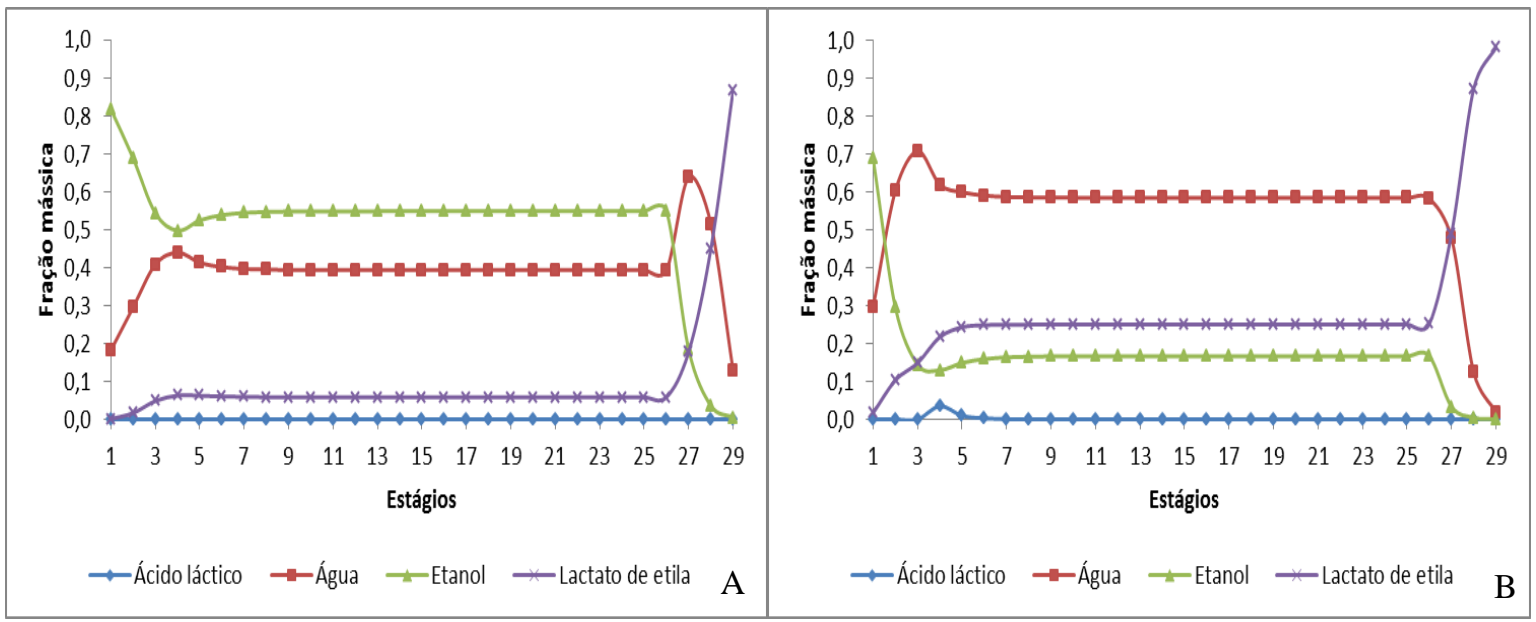

Figura2- Perfis das composições mássicas na fase vapor (A) e líquido (B) ao longo dos estágios da coluna de destilação reativa (RD1). 


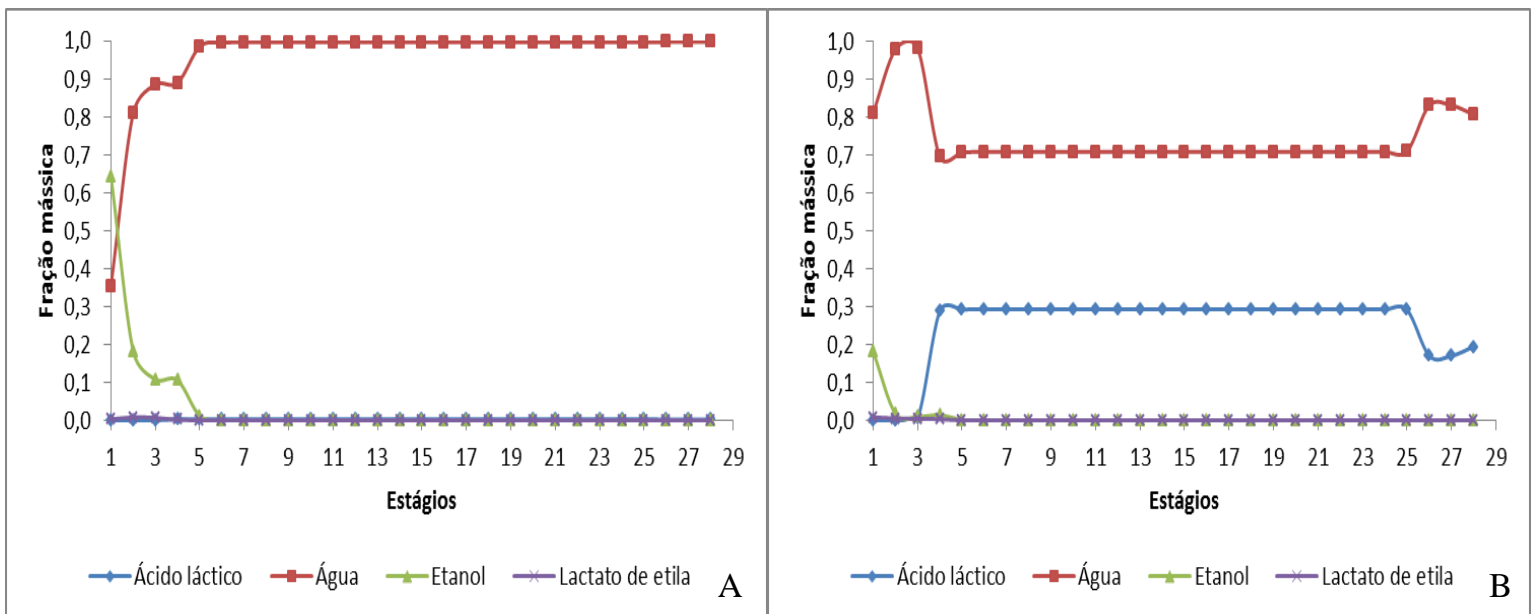

Figura 3- Perfis das composições mássicas na fase vapor (A) e líquido (B) ao longo dos estágios da coluna de destilação reativa (RD2).

As composições das correntes de produto das colunas RD1 e RD2 são mostradas naTabela 4. Lactato de etila com pureza em massa de $98,1 \%$ e ácido láctico com pureza em massa de 85,0 $\%$ foram obtidos na corrente de fundo da coluna RD1 e RD2, respectivamente.

Tabela 4- Correntes de produto da coluna RD1 e RD2

\begin{tabular}{lcccc}
\cline { 2 - 5 } & \multicolumn{2}{c}{ RD1 } & \multicolumn{2}{c}{ RD2 } \\
\cline { 2 - 5 } & Destilado & Resíduo & Destilado & Resíduo \\
\hline Vazão (kg/h) & 349,875 & 47,624 & 112,664 & 47,150 \\
Fração mássica de água & 0,296 & 0,019 & 0,810 & 0,150 \\
Fração mássica de etanol & 0,687 & $5,105 \mathrm{E}-04$ & 0,182 & $6,199 \mathrm{E}-08$ \\
Fração mássica de ácido láctico & $8,982 \mathrm{E}-10$ & $7,497 \mathrm{E}-13$ & $2,553 \mathrm{E}-6$ & 0,850 \\
Fração mássica de lactato de etila & 0,017 & 0,981 & $8,279 \mathrm{E}-3$ & $1,357 \mathrm{E}-05$ \\
\hline
\end{tabular}

Calculou-se o rendimento do lactato de etila e do ácido láctico. O rendimento do lactato de etila $\left(\mathrm{Y}_{\mathrm{LE}}\right)$ foi definido como o número de moles de lactato de etila formado pelo número total de moles de ácido láctico alimentado na coluna RD1 (Equação 4).O rendimento do ácido láctico $\left(\mathrm{Y}_{\mathrm{AL}}\right)$ foi definido como o número de moles de ácido láctico obtido na coluna RD2 pelo número de moles de ácido láctico alimentado na coluna RD1 (Equação 5).

$$
\begin{aligned}
& Y_{L E}=\frac{n^{\circ} \text { de moles de lactato de etila formado }}{n^{\circ} \text { total de moles de ácido láctico inicial }} \\
& Y_{A L}=\frac{n^{\circ} \text { de moles de ácido láctico obtido }}{n^{\circ} \text { total de moles de ácido láctico inicial }}
\end{aligned}
$$

O rendimento do lactato de etila $\left(\mathrm{Y}_{\mathrm{LE}}\right)$ foi de 0,889 e o rendimento do ácido láctico $\left(\mathrm{Y}_{\mathrm{AL}}\right)$ foi de 0,999. Esses elevados valores confirmam que o processo de purificação do ácido láctico proposto neste trabalho tem grande potencial para obtenção de ácido láctico com elevada pureza $(85,0 \%)$ e elevado rendimento de recuperação do ácido láctico $(0,999)$. 


\section{CONCLUSÕES}

Neste trabalho, foi proposta uma planta virtual para a purificação do ácido láctico proveniente da fermentação. Lactato de etila com pureza em massa de $98,1 \%$ foi obtido e alimentado na coluna de hidrólise gerando ácido láctico com pureza em massa de 85,0 \%.

A destilação reativa é uma técnica promissora para a recuperação de ácido láctico com elevada pureza e elevada conversão do caldo de fermentação, apresentando muitas vantagens: melhora na conversão dos reagentes, melhora na seletividade, redução da quantidade de catalisador entre outros.

\section{REFERÊNCIAS BIBLIOGRÁFICAS}

ASTHANA, N.; KOLAH, A.; VU, D.T.; LIRA, C.T.; MILLER, D.A continuous reactive separation process for ethyl lactate formation.Org. Process Res. \& Dev., v.9, p. 599607, 2005.

CAREY, J.S.; LEWIS, W.K. Studies in distillation.Liquid-vapor equilibria of ethyl alcoholwater mixtures.J. Ind. Eng. Chem., v.24, 882, 1932.

DELGADO, P.; SANZ, M.T.; BELTRAN, S. Kinetic study for esterification of lactic acid with ethanol and hydrolysis of ethyl lactate using an ion-exchange resin catalyst. Chem. Eng. J., v. 126, p. 111-118, 2007.

EDREDER, E.A.; MUJTABA, I.M.; EMTIR, M. Optimal operation of different types of batch reactive distillation columns used for hydrolysis of methyl lactate to lactic acid. Chem. Eng. J., 2011.

HAYDEN, J. G.; O'CONNELL, P.O. A generalized method for predicting second virial coefficients. Ind. Eng. Chem., Process Des.Dev., v.14, p. 209-216, 1975.

KUMAR, R.; MAHAJANI, S.M.; NANAVATI, H.; NORONHA, S.B. Recovery of lactic acid by batch reactive distillation.J. Chem. Technol. Biot., v. 81, p. 1141-1150, 2006 a.

KUMAR, R.; NANAVATI, H.; NORONHA, S.B.; MAHAJANI, S.M.A continuous process for the recovery of lactic acid by reactive distillation.J. Chem. Technol. Biot., v. 81, p. 1767-1777, 2006b.

LUNELLI, B.H.; ATALA, D.I.P.; OLIVEIRA, N.; WOLF MACIEL, M.R.; MACIEL FILHO, R. Ethyl lactate production using reactive distillation: experimental and simulation. J.Biotechnol., v.150, p.569, 2010.

MO, L.; SHAO-TONG, J.S.; LI-JUN, P.; ZHI, Z.; SHUI-ZHONG, L. Design and control of reactive distillation for hydrolysis of methyl lactate. Chem. Eng. Res. Des., 2011.

MUJTABA, I. M.; EDREDER, E. A.; EMTIR, M. Significant thermal energy reduction in lactic acid production process.Appl. Energ., v. 89, p. 74-80, 2012. 
OLIVEIRA, H. N. M. Determinação de dados de equilíbrio líquido-vapor para sistemas hidrocarbonetos e desenvolvimento de uma nova célula dinâmica. Natal: Engenharia Química, Universidade Federal do Rio Grande do Norte, 2003. Tese (Doutorado).

PEÑA-TEJEDOR, S.; MURGA, R.; SANZ, M.T.; BELTRÁN, S. Vaporliquidequilibriaandexcess volumes ofthebinary systems ethanol+ethyllactate, isopropanol+isopropyllactateandn-butanol+n-butyllactateat $101.325 \mathrm{kPa}$. Fluid Phase Equilibr., v.230, p. 197-203, 2005.

SANZ, M.T.; BELTRÁN, S.; CALVO, B.; CABEZAS, J.L. Vapor liquid equilibria of the mixtures involved in the esterification of lactic acid with methanol. J. Chem. Eng. Data, v.48, p.1446-1452, 2003.

SEO, Y.; HONG, W.H.; HONG, T.H. Effects of operation variables on the recovery of lactic acid in a batch distillation process with chemical reactions.Korean J. Chem. Eng, v. 16, p. 556-561, 1999.

WASEWAR, K.L.; HEESINK, A.B.M.; VERSTEEG, G.F; PANGARKAR, V.G. Reactive extraction of lactic acid using alamine 336 in MIBK: equilibria and kinetics. $J$ Biotechnol, v. 97, p. 59-68, 2002.

\section{AGRADECIMENTOS}

Os autores agradecem o apoio financeiro da FAPESP (Processo no 2012/17501-0). 